\title{
Effect of body mass index on intra-abdominal pressure in patients hospitalized in ICUs
}

\author{
Corresponding author: \\ Tahereh Khaleghdoost, Instructor \\ of Medical-Surgical Nursing Depart- \\ ment of Nursing, School of Nursing \\ and Midwifery Guilan University \\ of Medical Sciences, Iran \\ e-mail: crdu poursina@gums.ac.ir
}

Medical Research Journal 2021;

Volume 6, Number 1, 16-20 10.5603/MRJ.a2021.0044

Copyright (C) 2021 Via Medica

ISSN 2451-2591

e-ISSN 2451-4101

\begin{abstract}
Results: Considering the prevalence of obesity, overweight and risk factors related to the patients with Intra-abdominal pressure, the body mass index is among the factor which should be highly focused on these patients. The main objective of this study was to evaluate the effect of body mass index on Intra-abdominal pressure in patients hospitalized in ICUs.

Material and methods: The present research is a prospective, nonexperimental study conducted on 76 patients hospitalized in ICUs. Measurements of Intra-abdominal pressure were carried out based on the modified Korn method every day with 8-hour intervals. The instrument used for this purpose is a questionnaire consisting of three parts including demographic information, Sequential Organ Failure Assessment (SOFA) score, and intra-abdominal pressure monitoring form and record of its related parameters.

Results: The mean body mass index (BMI) scores revealed that $27.60 \%$ of the patients suffer from overweight and $7.2 \%$ of them have obesity problems with Intra-abdominal pressure of $8.44 \pm 4.02 \mathrm{mmHg}$. For $15.8 \%$ and $2.6 \%$ of samples, Intra-abdominal hypertension of types I and II were observed, respectively. No sample was detected within the abdominal compartment. The average Intra-abdominal pressure for different BMls indicated a statistically significant difference $(p=0.007)$, whereby an increase in BMI, IAP also indicates an increase. Conclusion: The present research indicated no obesity evidence so that no relation was observed between IAP and obesity.

Key words: body mass index, intra-abdominal pressure, ICU
\end{abstract}

Med Res J 2021; 6 (1): 16-20

\section{Introduction}

The abdomen is an enclosed space surrounded by different hard walls such as spines, pelvis, and ribs as well as soft walls such as abdomen wall, Viscera, and diaphragm that serves as a Liquid environment, so that, Intra-abdominal pressure (IAP) functioning is based on Pascal's Hydrostatic Laws [1]. According to this law, the IAP might be associated with individual anatomic characteristics such as body size, muscle tone or abdominal problems such as ascites, peritonitis, hemoperitoneum, and trauma [2]. Moreover, variations of IAP are related to Body Mass Index (BMI), obesity, and dynamics of the chest and abdomen. The normal IAP in healthy adults and critically ill patient adults is 0 to 5 and 5 to $7 \mathrm{mmHg}$, respectively $[1,3,4]$, while it is reported as 7 to $14 \mathrm{mmHg}$ for people with obesity $[1,3]$.
The studies show that $\mathrm{BMI}$ is responsible for 25 to $36 \%$ of IAP variations in critically ill patients [5]. Obesity is the direct responsibility of 300,000 annual death and a cost exceeding 100 billion dollars every year [6]. Recent studies have confirmed that prevalence and spread of Intra-Abdominal Hypertension (IAH) and abdominal compartment syndrome is associated with organ failure and mortality increase risks [7-9]. Based on previous studies, IAH in critically ill patients has been reported a range of 18 to $58.8 \%$. It must be noted that this wide range is related to different clinical (surgical or medical) environments, different measurement techniques, and different definitions and scales of IAH $[1,7,10]$. The World Society of the Abdominal Compartment Syndrome introduces BMI greater than $30 \mathrm{~kg} / \mathrm{m}^{2}$ or obesity among the risk factors of IAH [11]. Moreover, the prevalence of obesity in medical and surgical ICUs 
is reported up to $25 \%$ [12]. ICU patients have various $\mathrm{IAH}$ factors due to their particular conditions. Hence, due to the increasing rate of obesity and having other factors of IAH risk in this group of patients, it is highly recommended to pay special attention to $\mathrm{BMI}$ as one of IAH risk factors.

Assessment and measurement of IAP, similar to other hemodynamic parameters, are among the tasks of ICU nurses. Nurses should be particularly aware of IAP monitoring processes and their different aspects, as achieving these skills is necessary for the prognosis of patients exposed to the risk of IAH. By learning these skills, it is possible to reduce IAP and prevent the occurrence of ACS.

As previously mentioned, BMI is in close relation with IAP, and obese people are typically expected to have higher IAP. However, no study shows the effect of different BMI groups on IAP [13]. Considering the importance of $\mathrm{IAH}$ and attention of nurses to critical patients, this study was conducted to investigate the relationship between different $\mathrm{BMI}$ groups and other variables associated with IAP in ICU patients.

\section{Material and methods}

This analytical-sectional study was conducted to study the relationship between IAP and BMI in ICU patients. After obtaining a permit of the Ethics Committee of Guilan University of Medical Sciences, this research was conducted on 76 ICU patients hospitalized in educational health centres of Rasht. The criteria to enter this study are having age above 18 years, hospitalization in ICU and Ventilation with a ventilator for at least 24 hours, having Foley catheter and nasogastric tube, and Richmond agitation and sedation scores of -5 and -4 , respectively, lack of spine damage, and high ICP. Moreover, among the criteria to leave the research are intolerance to the recumbent position for measuring IAP as the homodynamic variations and respiratory distress.

The instrument applied in this research is extracted from the World Society of the Abdominal Compartment Syndrome which consists of three parts. Demographic information (age, gender, BMI, and disease prognosis index), Sequential Organ Failure Assessment (SOFA) score, and IAP monitoring and record of its related parameters (i.e., average artery pressure, mean airway pressure, maximum airway pressure, plateau pressure, positive airway pressure, and mode of ventilator machine).

The sampling process was performed from Nov $6^{\text {th, }}$ 2011 to Feb $4^{\text {th, }}$ 2012, for three months from ICUs of hospitals related to Guilan University of Medical Sciences. Among the 289 patients visited in ICU, 76 qualified patients entered the study after obtaining informed consent from their legal custodian. The measurement procedure for each trial (24 hours with 8-hour intervals), based on modified Korn method, was as: After selecting the given sample, Under sterile conditions a bottle with infusion liquid (sterilized $\mathrm{NaCl}$ $0.9 \%, 500 \mathrm{ml}$ ) connected with a three-way connector, One side is connected to a full catheter introduced transurethrally into the bladder and another side is connected to water monometer.

The patient was placed in a supine position. After marking the patient's skin in the crest iliac area on the mid-auxiliary line (for preventing changes in the following measurements), the zero point of water monument was adjusted with the marked area, then clumping the tube of urine bag, in the nearest place to the Foley probe of the patient and $25 \mathrm{ml}$ of sterilized saline normal solution with body temperature gently into the bladder. To create a balance between a patient's body after injecting normal saline solution and adjusting the patients at a head-of-bed angle, IAP and other pressure parameters were measured $60 \mathrm{sec}$ later. After $30 \mathrm{sec}$, the junction attached to the Foley probe was opened towards the water monometer and the IAP was recorded at end-expiratory after some respirations.

After IAP measurement was done, the clump is removed and the corresponding nurse is reminded to make sure the volume of normal saline injected into the bladder is less than the volume of urine output of the patient. Using the overhead monitoring system, the mean artery pressure of the patients were measured and recorded. Each IAP measurement took 7 to $8 \mathrm{~min}-$ utes. During the IAP measurements, in the case of IAH, the nurse and physician were informed about it to do required treatment measures. To measure BMI, height, and weight of patients, the information recorded in their medical file was used. Also, BMI categorization and measurement was carried out using the WHO classification (2000), where BMI $<18.5 \mathrm{~kg} / \mathrm{m}^{2}$ : less than normal weight, $18.50 \mathrm{~kg} / \mathrm{m} 2$ to $24.99 \mathrm{~kg} / \mathrm{m} 2$ : normal, 25 to $29.99 \mathrm{~kg} / \mathrm{m}^{2}$ : overweight, and BMl > $30 \mathrm{~kg} / \mathrm{m}^{2}$ : obesity.

\section{Statistical methods}

The obtained data were analyzed using descriptive and inferential statistics. Kolmogorov-Smirnov test was used to assess the normality of data. One-way ANOVA and the trend test were used to determine the significances of age, sex, and operative time differences between the three groups, and one-way ANOVA was used to assess intergroup differences concerning the relationship between IAP

ANOVA tests, using Bonferroni Post hoc, Pearson correlation coefficient using SPSS version 20 was used for data analysis. Statistical significance was accepted for $p$ values of $<0.05$. 


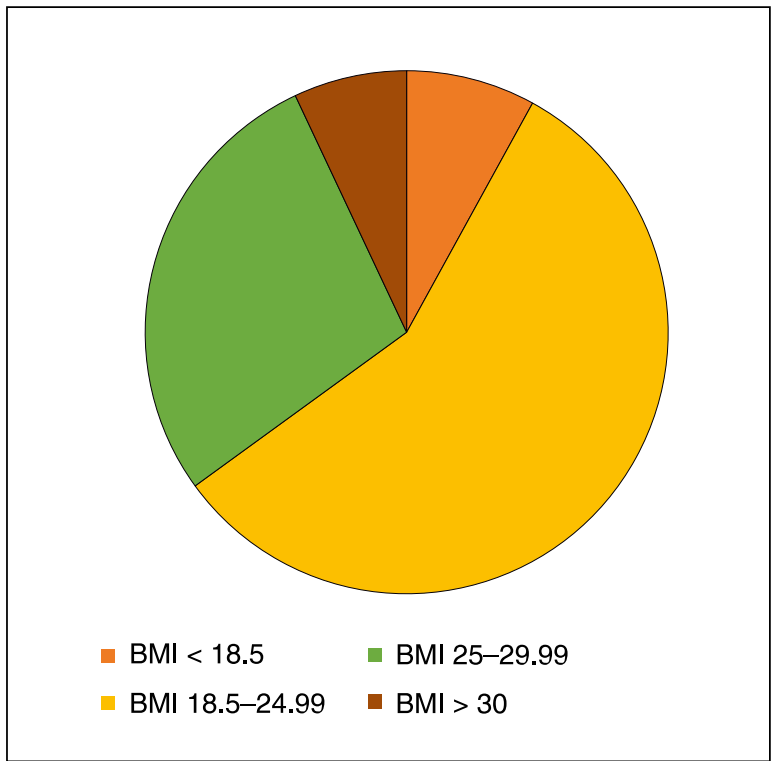

Figure 1. Distribution of participants according to BMI groups

\section{Results}

Based on the criteria for entering the research, 76 ICU patients selected from Rasht (Northern Iran) were studied in this research. The average age of patients was 50.31 years, while their mean BMl score was 23.7. Besides, $27.6 \%, 7.2 \%$, and $57 \%$ of the samples had overweight, obesity, natural weight, respectively; (Fig. 1) $60.5 \%$ of the samples were detected with trauma; 89.5\% were under SIMV mode ventilation; the average hospitalization age was 5.43 days (Tab. 1). Based on the results of this research, the mean IAP within 24 hours was $8.44 \pm 4.0262(81.58 \%)$ patients had normal IAP; (15.8\%) patients had IAH type I, and $2(2.6 \%)$ of them suffered from IAH type II. It must be noted that no patient had abdomen compartment syndrome.

Furthermore, there was found a significant relationship between IAP with SOFA score $(P<0.01)$ and hospitalization length $(P<0.01)$ and IAP with mean airway pressure, plateau pressure, positive end-expiratory pressure, and mean artery pressure $(P<0.01)$. Also, a significant relationship was found between IAP and age $(P<0.01)$ and prognosis $(P<0.04)$, as the mean $\mathrm{IAH}$ was higher for patients with internal problems as compared to those suffering from trauma. Finally, there was not a significant relationship between mean IAP and gender and mode of the ventilator system. The results also showed that average IAP indicates a statistically significant difference $(P=0.007)$ for at different $B M I$ levels and mean IAP rises with the increasing BMI (Tab. 2).

Body mass index as a risk factor for intra-abdominal hypertension by Post Hoc Bonferroni test was further
Table 1. Demographic and clinical characteristics of study population

\begin{tabular}{|c|c|}
\hline Variable & $\begin{array}{c}\text { Mean and standard } \\
\text { deviation }\end{array}$ \\
\hline \multicolumn{2}{|l|}{ Patient demographics } \\
\hline age [y] & $50.31 \pm 20.47$ \\
\hline BMI $\left[\mathrm{kg} / \mathrm{m}^{2}\right]$ & $23.70 \pm 6.94$ \\
\hline \multicolumn{2}{|l|}{ sex } \\
\hline Male & $55[72.4 \%]$ \\
\hline Female & $21[27.6 \%]$ \\
\hline \multicolumn{2}{|l|}{ Clinical characteristics } \\
\hline \multicolumn{2}{|l|}{ Diagnosis } \\
\hline Trauma & $46[60.5 \%]$ \\
\hline Medical & $30[39.47 \%]$ \\
\hline \multicolumn{2}{|l|}{ Mechanical ventilation } \\
\hline SIMV & $68[89.5 \%]$ \\
\hline BIPAP & $2[2.6 \%]$ \\
\hline CPAP & $6[7.9 \%]$ \\
\hline Length of stay [day] & $5.43 \pm 5.1$ \\
\hline SOFA & $6.85 \pm 3.07$ \\
\hline MAP [mmHg] & $95.15 \pm 17.66$ \\
\hline $\mathrm{PIP}\left[\mathrm{cmH}_{2} \mathrm{o}\right]$ & $26.59 \pm 6.93$ \\
\hline Plateau pressure $\left[\mathrm{cmH}_{2} \mathrm{O}\right]$ & $17.05 \pm 5.53$ \\
\hline Mean air way pressure $\left[\mathrm{cmH}_{2}\right.$ o] & $9.67 \pm 2.4$ \\
\hline APP $[\mathrm{mmHg}]$ & $86.71 \pm 1.65$ \\
\hline IAP [mmHg] & $8.44 \pm 4.02$ \\
\hline
\end{tabular}

BMI — Body mass index

SIMV - Synchronized intermittent mandatory ventilation

BIPAP — Bi-level positive airway pressure

CPAP - Continuous positive airway pressure

SOFA - Sequential Organ Failure Assessment

MAP - Mean arterial pressure

PIP — Peak inspiratory pressure

APP - Abdominal perfusion pressure

IAP — Intra-abdominal pressure

evaluated. It was shown that the average intra-abdominal pressure in obese $\left(\mathrm{BMI}>30 \mathrm{~kg} / \mathrm{m}^{2}\right)$ compared with overweight $\left(25-29.99 \mathrm{~kg} / \mathrm{m}^{2}\right)$ was significant. $(P<0.009)$ and also between obese subjects with normal BMI seen. $(P<0.021)$ (Tab. 3).

\section{Discussion and conclusion}

The results of this research showed that there is a statistically significant relationship between age and IAP, as by an increase in age, also IAP score rises. Murcia-Sáez et al (2010) also found a significant relationship between the ages and mean IAP in their research units 
[13]. This relationship was also significant in the work done by Ejika et al (2010) on patients younger than 18 years [14]. Considering the increased incidence

Table 2. Analysis of variables related to IAP

\begin{tabular}{lcc}
\hline Variable & $\begin{array}{c}\text { Mean and standard } \\
\text { deviation of IAP }\end{array}$ & Sig. \\
\hline Age (year) & $99.2 \pm 36.6$ & $<0.001$ \\
$18-35$ & $17.4 \pm 23.9$ & \\
$36-65$ & $08.4 \pm 68.9$ & \\
$>66$ & & 0.15 \\
Gender & $93.3 \pm 16.8$ & \\
Male & $24.4 \pm 17.9$ & \\
Female & & \\
Body mass index (BMI) & $23.2 \pm 84.10$ & \\
$<18.5$ & $10.4 \pm 04.8$ & \\
18.5-24.99 & $50.3 \pm 16.7$ & \\
$25-29.99$ & $13.3 \pm 62.12$ & \\
$>30$ & & 0.004 \\
Prognosis & $78.3 \pm 6.7$ & \\
Traumatic & $15.4 \pm 67.9$ & \\
Medical & & \\
Mode of ventilator system & $22.4 \pm 36.8$ & \\
SIMV & $95.0 \pm 02.8$ & \\
BIPAP & $77.1 \pm 51.9$ & \\
CPAP & & \\
\hline & & \\
& & \\
\hline & & \\
\hline
\end{tabular}

of different chronic and internal diseases by age, IAP increase is also probable in the patients. However, the work conducted by Vasquez et al (2007) does not show such a significant relationship between age and IAP [5].

In the matters of the relation between IAP and prognosis, it was shown that the mean IAP of the patients with trauma is less as compared to the patients with internal diseases (i.e., $7.6 \pm 3.78 \mathrm{mmHg}$ versus $9.67 \pm 4.15 \mathrm{mmHg}$ ), which is statistically significant. Based on the work conducted by McBeth et al (2007), the relation between IAP and prognosis of neurological illness is significant. In comparison, this relationship is not significant for surgical and traumatic patients [15]. In the study done by Malbrain et al (2004), no significant relation was found between prognosis of internal disease and traumatic diseases with IAP [2]. Likewise, the research conducted by Ejik et al (2010) on patients younger than 18 years indicated no relation between prognosis and IAP variations [14].

Based on the results of this research, no significant relation is observed between mean IAP score and SOFA score, hospitalization length, average airway pressure, plateau pressure, end-expiratory positive pressure, and mean artery pressure. The study conducted by Krebs et al (2009), "Effects of positive end-expiratory pressure on respiratory function and hemodynamics in patients with acute respiratory failure with and without intra-abdominal hypertension", indicated the presence of no statistically significant relation between plateau pressure and IAP [16].

Based on the results of this work, there is a significant relation between IAP and BMI. Vasquez et al (2007) reported a statistically significant relationship between

Table 3. Comparison of mean differences of IAP between BMI groups

\begin{tabular}{|c|c|c|c|c|c|}
\hline BMI & $\begin{array}{c}\text { Comparison } \\
\text { groups }\end{array}$ & $\begin{array}{c}\text { The mean } \\
\text { difference of IAP }\end{array}$ & Standard Error & Cl $95 \%$ & $\begin{array}{c}\text { Sig. } \\
\text { (Bonferroni } \\
\text { method) }\end{array}$ \\
\hline \multirow[t]{3}{*}{ BMI $<18.50$} & Normal & 2.69 & 1.75 & $-2.05,7.44$ & 0.76 \\
\hline & Overweight & 3.50 & 1.85 & $-1.53,8.53$ & 0.37 \\
\hline & Obesity & -2.24 & 2.23 & $-8.30,3.80$ & 0.1 \\
\hline \multirow[t]{3}{*}{$18.50-24.99$} & $\begin{array}{c}\text { Less than normal } \\
\text { weight }\end{array}$ & -2.69 & 1.75 & $-7.44,2.05$ & 0.76 \\
\hline & Overweight & 0.80 & 1.07 & $-2.09,3.71$ & 0.1 \\
\hline & Obesity & -4.94 & 1.63 & $-9.38,-0.50$ & 0.02 \\
\hline \multirow[t]{3}{*}{ 25.00-29.99 } & $\begin{array}{c}\text { Less than normal } \\
\text { weight }\end{array}$ & -3.50 & 1.85 & $-8.53,1.53$ & 0.37 \\
\hline & Normal & -0.80 & 1.07 & $-3.71,2.09$ & 0.1 \\
\hline & Obesity & -5.75 & 1.75 & $-10.50,-1.00$ & 0.009 \\
\hline \multirow[t]{3}{*}{$\mathrm{BMI}>30.00$} & $\begin{array}{c}\text { Less than normal } \\
\text { weight }\end{array}$ & 2.24 & 2.23 & $-3.80,8.30$ & 0.1 \\
\hline & Normal & 4.94 & 1.63 & $0.50,9.38$ & 0.1 \\
\hline & Overweight & 5.75 & 1.75 & $1.00,10.5$ & 0.009 \\
\hline
\end{tabular}


$\mathrm{BMI}$ and mean IAP and found that $\mathrm{BMI}$ is responsible for $25-36 \%$ of IAP variations [5]. Furthermore, McBeth et al found a significant relationship between $B M I$ and IAP. Cobb et al (2005) reported that IAP is related to $\mathrm{BMI}$ in healthy adults [17]. In another research, Rein tam et al (2008) found that patients suffering from IAH have higher BMI scores as compared to patients without $\mathrm{IAH}$ and $\mathrm{BMI}$ is detected as an independent risk factor for IAP increase [7]. On the other hand, the work performed by Malbrain (2000) indicated no significant relationship between high IAP and BMI [18]. Similarly, the study done by Vasquez et al (2007) on the study of BMI effect on IAP by comparing different BMI groups indicated that IAP does not have a significant difference in various BMI groups [5].

The present research indicated no obesity evidence so that no relation was observed between IAP and obesity. The previous researches, however, showed the chronic increase of IAP in patients with obesity [19].

It seems that the higher fat content around the abdominal cavity (central obesity) in people with higher BMI results in the increased IAP by direct impact on the abdominal cavity and pelvis bottom [3]. Considering the factors effective on IAP such as intestine compaction by the increase in BMI induced by the fats around the abdominal area, it is expected that the increase in BMI results in increased IAP.

Among the limitations of this research are lack of conducting work on the relationship between sagittal abdominal diameter (SAD) and IAP. The relationship between IAP and BMI might be majorly related to the central obesity of the abdominal area. For further works, it is suggested to organize a similar work in groups with $\mathrm{BMI}$ greater than 30 which involves people with obesity, as well as studying the relationship between IAP and SAD. Furthermore, it is recommended to use IAP as a part of the monitoring process in ICU and pay further attention to high $\mathrm{BMI}$ as an IAH risk factor.

\section{Acknowledgement}

We offer our gratitude to the research deputy of Guilan University of Medical Sciences for supplying the budget needed in this research, the members of research board, and staffs from ICU and educational units of Poursina Hospital, Rasht. This paper is extracted from special M.Sc. theses passed in research deputy of Guilan University of Medical Sciences with the registration number: N2010102147872.

\section{References}

1. Mabrain ML, Chiumello D, Pelosi P, et al. Prevalence of intra-abdominal hypertension in critically ill patients: a multi-center epidemiological study. Intensive Care Med. 2004; 30(5): 822-9.

2. Gallagher J. , Intra-abdominal Hypertension, AACN Advanced Critical Care. 2010; 21(2): 205-217.

3. De K, De W, Powell B, et al. What is normal intra-abdominal pressure and how is it affected by positioning, body mass and positive end -expiratory pressure? Intensive Care Med. 2009; 35: 969-976.

4. De Waele JJ, Cheatham ML, Malbrain ML, et al. Results from the International Conference of Experts on Intra-abdominal Hypertension and Abdominal Compartment Syndrome. I. Definitions. Intensive Care Med. 2006; 32(11): 1722-1732, doi: 10.1007/s00134-006-0349-5, indexed in Pubmed: 16967294

5. Vasquez DG, Berg-Copas GM, Wetta-Hall R. Influence of semi-recumbent position on intra-abdominal pressure as measured by bladder pressure. J Surg Res. 2007; 139(2): 280-285, doi: 10.1016/j. iss.2006.10.023, indexed in Pubmed: 17161433

6. Subak LL, Richter HE, Hunskaar S. Obesity and urinary incontinence: epidemiology and clinical research update. J Urol. 2009; 182(6 Suppl): S2-S7, doi: 10.1016/j.juro.2009.08.071, indexed in Pubmed: 19846133.

7. Yi M, Leng Y, Bai Yu, et al. The evaluation of the effect of body positioning on intra-abdominal pressure measurement and the effect of intra-abdominal pressure at different body positioning on organ function and prognosis in critically ill patients. J Crit Care. 2012; 27(2): 222.e1-222. e6, doi: 10.1016/j.jcrc.2011.08.010, indexed in Pubmed: 22033056.

8. Kimball EJ, Rollins MD, Mone MC, et al. Survey of intensive care physicians on the recognition and management of intra-abdominal hypertension and abdominal compartment syndrome. Crit Care Med. 2006; 34(9): 2340-2348, doi: 10.1097/01.CCM.0000233874.88032.1C, indexed in Pubmed: 16878034.

9. Rein ta, Parm P, Kern H, et al. Primary and secondary intra-abdominal hypertension different impact on ICU outcome. Intensive Care Med. 2008; 34: 1624.

10. Malbrain M, Chiumello D, Pelosi $P$, et al. Incidence and prognosis of intra-abdominal hypertension in a mixed population of critically ill patients: a multiple-center epidemiological study. Crit Care Med. 2005; 33: 315-322.

11. Santa-Teresa P, Muñoz J, Montero I, et al. Incidence and prognosis of intra-abdominal hypertension in critically ill medical patients: a prospective epidemiological study. Ann Intensive Care. 2012; 2 Suppl 1: S3, doi: 10.1186/2110-5820-2-S1-S3, indexed in Pubmed: 22873419.

12. Aaron J. Wood. , Obesity in critically care, current opinion Anesthesiology. 2007; 20(2): 113-8.

13. Murcia I, et al. Sobbing- Hernandez M., Garcia- lopes n. Usefulness of intra-abdominal pressure in a predominantly medical intensive care unit Journal of critical care. ; 2010: 25175e1-175e6.

14. Ejike JC, Kadry J, Bahjri K, et al. Semi-recumbent position and body mass percentiles: effects on intra-abdominal pressure measurements in critically ill children. Intensive Care Med. 2010; 36(2): 329-335, doi: 10.1007/s00134-009-1708-9, indexed in Pubmed: 19898835.

15. McBeth PB, Zygun DA. Widder S, et al. Effect of patient positioning on intra-abdominal pressure monitoring. Am J Surg. 2007; 193(5): 644-7; discussion 647, doi: 10.1016/j.amjsurg.2007.01.013, indexed in Pubmed: 17434374

16. Krebs J, Pelosi P, Tsagogiorg C, et al. Effect of positive end-expiratory pressure on respiratory function and hemodynamics in patients with acute respiratory failure with and witnout intra-abdominal hypertension: a pilot study. crit care. 2009; 13(5): R160.

17. Cobb WS, Burns JM, Kercher KW, et al. Normal intraabdominal pressure in healthy adults. J Surg Res. 2005; 129(2): 231-235, doi: 10.1016/j. jss.2005.06.015, indexed in Pubmed: 16140336

18. Malbrain M. Relationship of body mass index (BMI), lactate and intra-abdominal pressure (IAP) to subsequent mortality in ICU patients. Critical Care. 1999; 3(Suppl 1): P039, doi: 10.1186/cc414.

19. Hon I, WuK So, Hyup Na, et al. Hon I, WuK Son D, Hyup Nam K, Chio $B$, Sung Song $G$, The effect of body mass index on intra-abdominal pressure and blood loss in lumbar spine surgery, J Korean Neurosurg Soc. 2012; 51: 81-85. 